\title{
English Learners' Cognitive Adjustment in Network Multimedia Assisted Learning Environment
}

\author{
Binjie Chen \\ Zhengzhou University of industrial technology, Henan, China
}

\begin{abstract}
Multimedia, as one of the new English teaching and learning assistance, is challenging the traditional teaching and learning approaches. Multimedia results from the development of society and the modern technology and is a breakthrough of the computer teaching and learning technology. In a network multimedia learning environment, many students' performance suffers because of poor ability in independent learning, self-supervision and introspection. Strategies to improve the cognitive ability of the learners are proposed based on an analysis of the internal and external factors that affect the learner's cognitive ability in a network multimedia environment. Based on the continuous development of the modern technology, the multimedia teaching and learning mode is widely applied. Multimedia, applied in the English teaching and learning process, create more authentic language environments, which enable the learners to communicate in English in real-life situations. Because both the authentic environment and communicative purposes are encouraged in modern EFL (English as a Foreign Language) teaching and learning classes, the combination of multimedia and basic teaching and learning skills will be a necessity. It is proved that the combination of the two is an effective way in the modern English language classes.
\end{abstract}

Keywords: network multimedia; assisted learning; cognitive adjustment.

\section{Introduction}

Since students have different responses to information, it is better for the teachers to use different formats and modes so as to teach the main content of a lesson. Therefore, teachers normally use the combination of lectures, texts and hands-on laboratories to convey information. With the advent of the internet era, people nowadays have several new and exciting ways to present information. The internet allows English lessons to connect with animations, moving pictures, and sounds, which can not only extend the teaching methods, but also encourage students to interact with the main content. Pictures and animations help bring scientific principles to life, while multimedia allow students to take a more active role in learning: they can watch experiment actions and use a mouse or a keyboard to navigate images, simulations and interactive materials. One of the advantages of using multimedia is to convey information quickly and effectively to all students, and keep them interested in learning.Multimedia learning came into being with the development of information technology. Multimedia computer and computer networks are at the heart of this teaching mode, dramatically changing the transmission, storage, processing, retrieval and display of information. This learning style is greatly superior to those using other media. Guided by modern educational theories, multimedia learning can promote the reform of existing teaching structures and organizations.

English language learning broadens students' horizons in understanding other countries' cultures, and way of thinking, etc. Therefore, English, as a subject, is being paid more and more attention in the school. But in Chinese English classes, which are usually influenced by traditional English teaching and learning methods, students may not understand native English peakers' words or they do not know how to express their own ideas, even though they have already learned English for 10 years. That is because most teachers use their demode methods to teach students English. In fact, the traditional English teaching and learning mode misleads students. Before students are not fully prepared in classes, the teachers compel them to make sentences with language skills and grammar rules. As a result, it is easy for the students to feel frustrated, and consequently their English standard is only 'deaf mutes' English, namely, students can only develop strong reading \& writing skills while have weak speaking \& listening abilities. Therefore, traditional English teaching and learning mode is difficult to meet the needs of the modern society. Multimedia, as one of the new English teaching and learning assistance, is challenging the traditional teaching and learning approaches. Multimedia 
results from the development of society and the modern technology and is a breakthrough of the computer teaching and learning technology.

Learning style in a multimedia environment stresses the importance of students, who are the learning subjects and active constructors of knowledge. Teachers are the organizers, guides and designers of the teaching. Information technologies provide the tools for students' cognition and motivation. This interactive, open and initiative-based learning can also leverage students' enthusiasm and creativity, as well as guide them to acquire knowledge in their own, personalized way [1].

Distance education is regarded as an important part of the Chinese national education development strategy, as it is important for the building of a lifelong learning and learning-oriented society. However, there are many difficulties in distance learning regarding autonomous learning, selfmonitoring and reflection. In this article, the author presents and discusses methods to improve learners' cognitive adjustment in a network multimedia learning environment based on external factors.

\section{Improving cognition adjustment in a network multimedia learning environment}

\subsection{Maintaining Learning Motivation to Promote Cognitive Dissonance}

Motivation of students' learning in a net multimedia environment is different from that in traditional class. The means to motivate belong to the network class designer. Here, one can draw from TC (time continuum) motivation model theory [3].

These show how to improve the learning and make the students more interested. This mode focuses on the teaching process and divides motivation into six aspects, viz. situation, need, stimulation, emotion, ability and intensification [4]. Motivation in the learning process is considered to be dynamic and changeable.

This mode analyses the motivation elements at the start of teaching, during the teaching, and at the end of teaching, as shown in Figure 1.

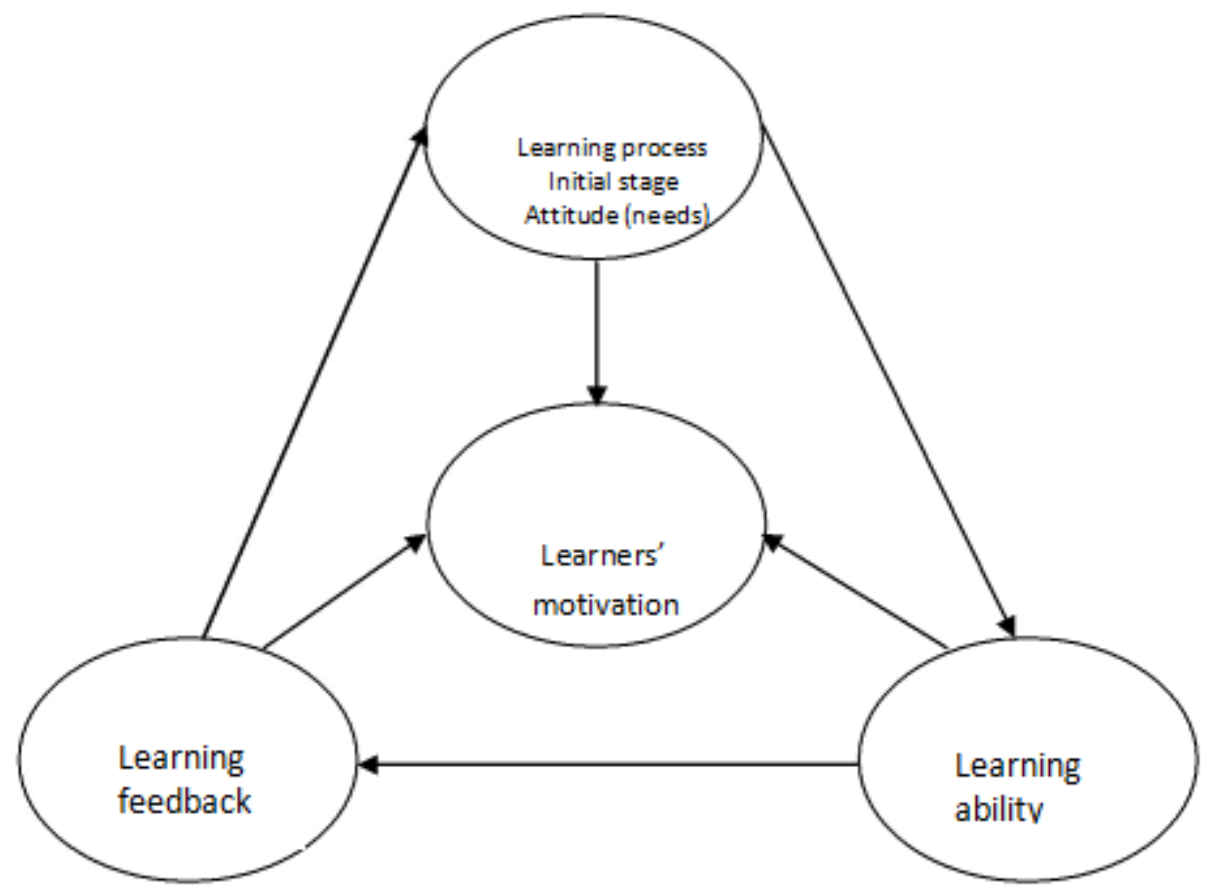

Figure 1 Mode of stimulating learning motivation.

\subsection{Stress successful experiences}

Before the network learning, teachers should introduce the advantages of network learning to students, particularly those new to network learning. Teachers can also cover successful network learning cases or visit experienced successful learners, to introduce the advantages of network learning, as well as the problems. This should enhance learners' confidence in network learning. 


\subsection{Encouraging self-efficacy}

When evaluating network learners, particularly by formative evaluation, stress should be placed on personal efforts and abilities, as well as on other internal controllable elements, for learners with high self-efficacy. By comparison, stress should be placed on the external uncontrollable elements for learners with low self-efficacy, so as not to reduce their self-efficacy.

\subsection{Effect of physiology and emotion}

When judging self-ability, people depend on physical and psychological information. People are more likely to have a high expectation of success when they are not suffering negative emotions, and are not anxious or fretful. A learner's attention level is a physical condition influencing self-efficacy. The less attention paid to learning, the more attention is paid to this unsound physical state. To reduce the influence of a learner's physiology and of negative emotions, the network course designers should carefully include pictures and other multimedia learning content, so as to attract students' attention on network courses. But, there does not need to be too much perceptual stimulation. Clear goals and simple style are enough, so as to avoid being a distraction.

\section{Metacognition to Improve Cognitive Adjustment}

In network learning, learners will face various kinds of difficulties because of the independent learning rather than the systematic instruction by teachers. Designers of network learning courses should consider all possible difficulties and try to identify solutions, which is a challenge facing the designer. In traditional teaching, teachers design courses, which are conducive to student learning centred on classroom teaching, with specific learning points. In a multimedia environment, many teaching strategies can be adopted, such as an entering learning strategy or anchoring method.

Teaching materials on the network are interconnected and the study is open. Learners in a network learning situation are likely to deviate from their learning points and place too much emphasis on details, while ignoring the important themes. Under such conditions, learners should self-plan their cognition and learning.

At the beginning of network learning, an electronic notepad could be opened for students to write down their study plan, and their expectations; thus, internalising their learning goals. This plan could be made available by a single touch button, so learners can review their learning plans anytime. This encourages learning to be centred on the teaching goals by guiding students not to deviate from these goals. For successful students with high motivation and who are good at studying on the net, this method could be a barrier to their study and the single touch button might be greyed-out or unavailable.

In traditional teaching, teachers learn of students' understanding by their performance and by questioning. Teachers take relevant measures to ensure they have a deep and comprehensive explanation for issues students do not understand. Teachers can provide individual assistance if necessary. In the network multimedia environment, students themselves need to supervise the cognition process, pay attention to information and ask themselves questions. They control the steps in their learning, allocate their learning time and conduct formative evaluation in the learning process. When designing courses, to guide students, designers can underscore important information with different colours and typefaces. When students tackle difficult knowledge areas, designers can include prompts to help learners.

If students find they do not understand certain material, they can check whether their cognitive strategies are appropriate and whether there are shortcomings in their basic knowledge. Successful learners can quickly find solutions to problems; they transfer their cognitive strategies or supplement their basic knowledge. But, other learners need guidance. When designing network courses, designers should identify the important parts and potential problems. This feeds into help menu designs and areas requiring detailed information. However, it is better not to tell learners about their knowledge deficiencies. It is better to use a design mode based on the zone of proximal development of Lev Vygotsky. In addition, for difficult content, learners can consult the experts by e-mail and carry out discussions with teachers and classmates.

Study folders serve as an effective tool by which students' performance can be evaluated. Learners can put their creative and personalised electronic work in the folder. Thus, students will feel 
satisfaction seeing their results and this will improve their confidence in network learning. Network course designers need to design creative, open and challenging problems, to encourage students to bring their imagination and creativity into play. Teachers should have timely comments on students' homework, with a focus on learners' creative, personalised learning and an appreciation of student progress. When students have an incorrect understanding of a problem, it is better for teachers to guide students, put forward questions and, then, let students rethink and question rather than directly saying they are wrong. After careful reflection, students will develop the right understanding of the problem without it causing a loss of confidence and enthusiasm. By these means, learners are more willing to study through the network and improve their cognitive adjustment.

\section{Conclusion}

In conclusion, how to manage teaching and learning is a complex process in the EFL class. Teachers should create authentic situations for students to learn English as much as possible by using multimedia. They should also provide students more chances to practice English and to improve their communication abilities. Teachers need to arrange activities clearly so that students will know what they are required to do. Successful teachers can make good control over the class as well as the time. EFL teachers need to try new teaching and learning approaches/techniques and make evaluations, as well. Assisted with multimedia, teachers should follow the Communicative Language skills, namely, to combine Communicative Language skills with multimedia which is based on computers (the internet).

\section{References}

[1] Cohen A D.Strategies in Learning and Using a Second Language [C].Foreign Language Teaching and Research Press, 2000.

[2] Harmer J.How to Teach English. Foreign Language [J].Teaching and Research Press, 2000.

[3] Richards J C.The Context of Language Teaching [J].Cambridge University Press, 1998.

[4] Ur P.A Course in Language Teaching: Practice and Theory [C]. Cambridge University Press, 1996.

[5] Cook V.Second Language Learning and Language Teaching [C].Edward A rnold Limited,1991. 